\title{
General and oral health status of preterm one-year-old very low and extremely low birthweight infants (a cross - sectional study)
}

\author{
Vlasta Merglovaa, Lukas Hauera , Zdenek Broukal ${ }^{b}$, Jiri Dortc, Romana Koberova Ivancakova ${ }^{d}$
}

\begin{abstract}
Aims. The aim of the present study was to evaluate the general and oral health status of a group of preterm one-yearold very low (VLBW) and extremely low birthweight (ELBW) infants and make a comparison with full-term one-year-old normal birthweight infants (NBW).

Methods. A cross-sectional study was conducted in 102 one-year-old preterm VLBW and ELBW infants, and the data obtained were compared to 87 one-year-old full-term NBW infants. The infants' medical histories were obtained from hospital records and interviews with the mothers. The oral cavities of all infants were examined under the same conditions. The chi-square test, Pearson's chi-square test of independence and Mann-Whitney test were used for the statistical evaluation, with $P<0.05$ considered statistically significant. Relative risk (RR) and 95\% confidence interval (Cl) estimates for variables significantly associated with oral findings were calculated.

Results. Both perinatal variables (gestational age, mode of delivery, birthweight, Apgar score, resuscitation, orotracheal intubation and presence of intraoral pathology) and neonatal variables (antibiotic treatment and infections) had a significant association with prematurity, VLBW and ELBW. The one-year-old preterm VLBW and ELBW infants frequently suffered from general diseases, frequently received regular medication and had fewer erupted primary teeth; they also had a higher prevalence of developmental defects of the enamel and deformations of the hard palate.

Conclusion. This study confirmed anamnestic, medical and oral differences between one-year-old preterm VLBW and ELBW and full-term NBW infants.
\end{abstract}

Key words: preterm infant, very low birthweight, extremely low birthweight, primary teeth, developmental enamel defect, deformation of the hard palate

Received: November 15, 2019; Revised: February 25, 2020; Accepted: March 3, 2020; Available online: March 17, 2020 https://doi.org/10.5507/bp.2020.009

(c) 2021 The Authors; https://creativecommons.org/licenses/by/4.0/

${ }^{a}$ Department of Dentistry, Faculty of Medicine in Pilsen, Charles University and University Hospital in Pilsen, Czech Republic bInstitute of Clinical and Experimental Dental Medicine, $1^{\text {st }}$ Faculty of Medicine, Charles University in Prague, Czech Republic 'Department of Neonatology, Faculty Hospital in Pilsen, Czech Republic

${ }^{d}$ Department of Dentistry, Faculty of Medicine in Hradec Kralove, Charles University and University Hospital in Hradec Kralove, Czech Republic

Corresponding author: Vlasta Merglova, e-mail: merglovav@fnplzen.cz

\section{INTRODUCTION}

Preterm birth and low birthweight are the main factors of early morbidity and mortality in neonates and late morbidity in infants across the world. According to the definition of the World Health Organization ${ }^{1}$, a preterm infant is defined as one born before completing gestational week 37. Low birthweight (LBW) is defined as weighing less than $2500 \mathrm{~g}$, regardless of gestational age. LBW includes both appropriately grown preterm infants and term and preterm growth-restricted neonates. Blencowe et al. ${ }^{2}$ estimated an LBW prevalence of 6.8-7.2 per 100 livebirths for 2000-2015 in developed countries (North America, Europe, Australia and New Zealand). Low birthweight neonates are additionally subdivided into very low birthweight infants (VLBW), with birthweight $<1500 \mathrm{~g}$, and extremely low birthweight infants (ELBW), with birthweight $<1000 \mathrm{~g}$. Preterm birth is frequently associated with LBW, VLBW or ELBW. Premature infants, especially those with VLBW and ELBW, have a shorter prenatal period and are predisposed to various perinatal and neonatal complications and developmental problems that can affect their general growth and progress during infancy and throughout childhood. Premature VLBW and ELBW infants are prone to suffer from many serious conditions, such as breathing problems, patent ductus arteriosus, anemia, immunodeficiency, hypocalcemia, osteopenia, visual and hearing disorders and other alterations that affect development and growth ${ }^{3}$. These complications may be associated with poor feeding, lack of optimal nutrition, and vitamin and mineral deficiencies ${ }^{4}$. Some treatments and techniques to sustain life in preterm VLBW and ELBW infants have a negative impact on oral development. The developmental enamel defects (DDE) of the primary incisors, dilacerations of the primary incisors and anomalies of the hard palate may be connected with laryngoscopies and orotracheal intubations ${ }^{5-7}$. Preterm VLBW and ELBW infants are also at increased risk of delayed tooth eruption, DDE in permanent dentition, tooth discoloration and tooth crown dimension changes ${ }^{8-12}$ 
The aim of the study was to evaluate anamnestic and medical data and oral conditions in one-year-old VLBW and ELBW preterm infants and compare these findings with one-year-old full-term normal birthweight NBW infants.

\section{MATERIALS AND METHODS}

This cross-sectional study is part of a long-term research project supported by the Ministry of Health, Czech Republic, being conducted at the Departments of Dentistry and Neonatology, Faculty Hospitals in Pilsen and Hradec Kralove, Czech Republic. All infants were enrolled in the current study at birth by the Departments of Neonatology, Faculty Hospitals in Pilsen and Hradec Kralove, Czech Republic. Preterm VLBW and ELBW Caucasian neonates of both sexes were selected according to inclusion and exclusion criteria, and the same therapeutic principles were used during their perinatal and neonatal hospital care. A convenience sample, including full-term neonates with NBW, was used, and these neonates were recruited at the Neonatological Departments in Pilsen and Hradec Kralove. After birth, the oral cavities of the preterm VLBW and ELBW neonates and full-term NBW neonates were examined, and oral pathological conditions were recorded. The first dental examination of all the neonates was recommended at the corrected age of one year.

Gestational age $<37$ weeks and birthweight $<1500 \mathrm{~g}$ were the inclusion criteria for the preterm VLBW and ELBW group, and gestational age $>37$ weeks and birth weight $>2500 \mathrm{~g}$ were the inclusion criteria for full-term NBW neonates. The gestational age was estimated from the result of ultrasound examinations during pregnancy. A further inclusion criterion for both groups of neonates was self-perceived socioeconomic class of the parents. The exclusion criteria were the presence of systemic disease or immunological deficiency in the full-term group and genetic syndromes and malformations diagnosed during the neonatal period in the preterm VLBW and ELBW group.

The total number of preterm VLBW and ELBW neonates born during the evaluation period (2015-2016) was 242. Fewer infants were included in the final study sample for various reasons (newborn death, serious health complications, parental disapproval of participation in the study, remote residence, native language other than Czech, and abandonment of outpatient follow-up during the period of data collection). Preterm VLBW and ELBW infants were referred from the Developmental Centers of Neonatology Departments in Pilsen and Hradec Kralove, Czech Republic, for their first dental examination at the corrected age of one year. As prematurely born infants are not fully mature at the time of birth, their chronological ages do not correspond to their true biological ages. Hence, a comparison with full-term infants can only be made if the age of the preterm infants is corrected. The corrected age was calculated by subtracting the number of weeks born before 40 weeks of gestation from the chronological age. Full-term NBW infants were invited for their first dental examination at the chronological age of one year.

The total number of preterm VLBW and ELBW infants and full-term NBW infants that passed the examination during the neonatal period and completed follow-up at the corrected or chronological age of one year was 200. Out of the 200 examined infants, 11 were excluded (parental lack of interest to continue in the study). The final research cohort was composed of 189 one-year-old infants of both sexes, 102 of whom were born prematurely with VLBW or ELBW and 87 of whom were delivered at full-term with NBW.

The infants' medical histories were obtained from the hospital records and interviews with the mothers. All infants included in the study were residents of communities with low natural fluoride content $(<0.3 \mathrm{ppm})$. Two previously trained and calibrated examiners at the Pediatric Dentistry Departments in Pilsen and Hradec Kralove, Czech Republic, performed the dental examination on all infants. The dental examiners were blinded to the infants' groups. The oral cavity of the infants was examined under ideal conditions using a sterile dental mirror, dental probe and artificial light, while the infants were held in their parents' lap. All erupted teeth were recorded in the dental chart. A tooth was considered erupted if any part of its crown had penetrated the oral mucous. The teeth were dried with gauze, and then dental mirrors and probes were used for the detection of DDE. DDE were recorded on the labial surface of each tooth. Defects measuring less than one millimeter were excluded, and when any doubt existed concerning the presence of DDE, the tooth was scored as being without enamel defects ${ }^{13}$. The alteration of primary teeth enamel was classified according to the Modified Developmental Defects of Enamel Index, suggested by the Commission on Oral Health, Research and Epidemiology ${ }^{14}$. Clinically, DDE can be classified into three types: demarcated opacity, diffuse opacity and hypoplasia. Opacities (hypomineralizations) are qualitative changes in enamel translucency without loss of enamel surface. Demarcated opacities are defects of enamel mineralization that are distinct from the adjacent healthy enamel and may present a white, creamy, yellow or brown color. Diffuse opacities comprise alterations in enamel translucency of variable degree and are white in color. There is no clear demarcation between normal enamel and opacity. Hypoplasia is a quantitative defect affecting the enamel surface; it is associated with reduced enamel thickness and can manifest as pits, grooves or other surface loss. Color photographs showing typical examples of different types of DDE were used as a guide in scoring the teeth for $\mathrm{DDE}^{15}$. The opacities were differentiated from white spot carious lesions based on color, texture, demarcation and relationship to the gingival margin ${ }^{15}$. Deformations of the hard palate (palatal grooving, high arch palate, palatal asymmetry) were diagnosed visually using the description of Ehrenberg and Nowak ${ }^{16}$.

The following variables were recorded for each infant: birthweight, mode of delivery, gestational age, Apgar score, resuscitation, laryngoscopy, antibiotic treatment, infections, general diseases, and regular medication. The 
Apgar scoring system is a commonly used comprehensive screening tool to evaluate a newborn's condition at birth. The Apgar score is recorded at one, five and $10 \mathrm{~min}$ of life. Newborns are evaluated based on five variables: heart rate, respiratory effort, muscle tone, reflex irritability and skin color ${ }^{17,18}$. For this study, the presence of oral pathology was evaluated in all neonates. Variables involving oral conditions in the one-year-old infants were the number of erupted primary teeth, presence of DDE and deformation of the hard palate.

\section{Statistical analysis}

The data were statistically analyzed using Statgraphics software distributed by Stat Point Technologies, Inc. of Warrenton, Virginia, USA. The comparison between the two groups was conducted using the chi-squared test for evaluation of the mode of delivery, need for resuscitation and laryngoscopy, antibiotic treatment, presence of infections, general diseases, regular medication, developmental enamel defects and oral pathology. The t-test was used for comparisons of gestational age, birthweight and Apgar scores. For comparison of the number of erupted teeth in preterm VLBW and ELBW and full-term NBW infants, the Mann-Whitney test was applied; in cases of hard palate deformation, Pearson's chi-squared test of independence was used. A statistical significance level of $P<0.05$ was established. Relative risk (RR) and 95\% confidence interval (CI) estimates for the variables significantly associated with oral findings were calculated using the online Med Calc tool (http://www.medicalc-org/calc/ relative_risk.php).

\section{Ethical considerations}

Ethical approval for the investigation was obtained from the Research Ethics Committee Faculty of Medicine in Pilsen and Hradec Kralove, Charles University in Prague, Czech Republic. The study was conducted in accordance with the Helsinki Declaration of 1975, as revised in 1983. All infants were recruited from the Department of Neonatology of the Faculty Hospitals in Pilsen and Hradec Kralove, Czech Republic. Prior to the study, the legal guardians of all infants provided informed consent for their children to participate in the research.

\section{RESULTS}

\section{Characteristics of the subjects}

The characteristics of the preterm VLBW and ELBW and full-term NBW infants are summarized in Table 1.

Table 1. Perinatal and neonatal variables.

\begin{tabular}{|c|c|c|c|}
\hline Variables & Preterm VLBW and ELBW & Full - term NBW & $P$ \\
\hline \multicolumn{4}{|l|}{$\mathrm{N}(\%)$} \\
\hline Birthweight $(\mathrm{g})$ : Mean $\pm \mathrm{SD}^{* *}$ & $1148.9 \pm 285.3$ & $3418.6 \pm 285.3$ & $<0.0001$ \\
\hline \multicolumn{4}{|l|}{ Mode of delivery* } \\
\hline Vaginal & $12(11.8)$ & $71(81.6)$ & \multirow{2}{*}{$<0.0001$} \\
\hline Sectio caesarea & $90(88.2)$ & $16(18.4)$ & \\
\hline Gestational age (wks): Mean \pm SD** & $29.38 \pm 2.73$ & $39.36 \pm 1.07$ & \\
\hline \multicolumn{4}{|l|}{ Apgar score** } \\
\hline 1 & $6.78 \pm 1.9$ & $9.66 \pm 0.34$ & $<0.0001$ \\
\hline 5 & $8.00 \pm 0.99$ & $9.84 \pm 0.16$ & $<0.0001$ \\
\hline 10 & $8.53 \pm 0.85$ & $9.95 \pm 0.05$ & $<0.0001$ \\
\hline \multicolumn{4}{|l|}{ Resuscitation* } \\
\hline No & $69(67.6)$ & $84(96.6)$ & \multirow{2}{*}{0.0002} \\
\hline Yes & $33(32.4)$ & $3(3.4)$ & \\
\hline \multicolumn{4}{|l|}{ Laryngoscopy* } \\
\hline No & $43(42.2)$ & $87(100.0)$ & \multirow{2}{*}{$<0.0001$} \\
\hline Yes & $59(57.8)$ & 0 & \\
\hline \multicolumn{4}{|l|}{ Atb treatment* } \\
\hline No & 0 & $87(100.0)$ & \multirow{2}{*}{$<0.0001$} \\
\hline Yes & $102(100.0)$ & 0 & \\
\hline \multicolumn{4}{|l|}{ Infections* } \\
\hline No & $52(51.0)$ & $87(100.0)$ & \multirow{2}{*}{$<0.0001$} \\
\hline Yes & $50(49.0)$ & 0 & \\
\hline \multicolumn{4}{|l|}{ General diseases* } \\
\hline No & $78(76.5)$ & $84(96.6)$ & \multirow{2}{*}{$<0.0001$} \\
\hline Yes & $24(23.5)$ & $3(3.4)$ & \\
\hline \multicolumn{4}{|l|}{ Medication* } \\
\hline No & $94(92.2)$ & $87(100.0)$ & \multirow{2}{*}{0.0196} \\
\hline Yes & $8(7.8)$ & 0 & \\
\hline
\end{tabular}

\footnotetext{
${ }^{*} \chi^{2}$ test, ${ }^{* *}$ t-test
} 


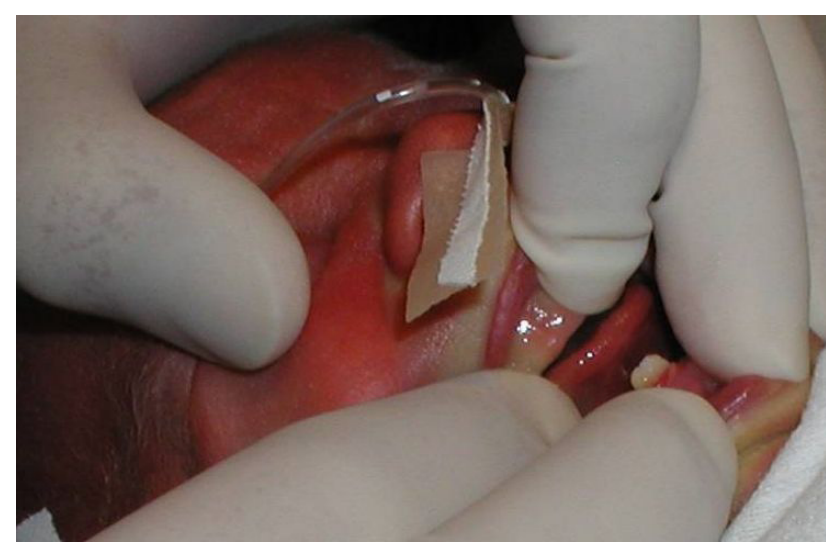

Fig. 1. Neonatal lower incisor in preterm neonate.

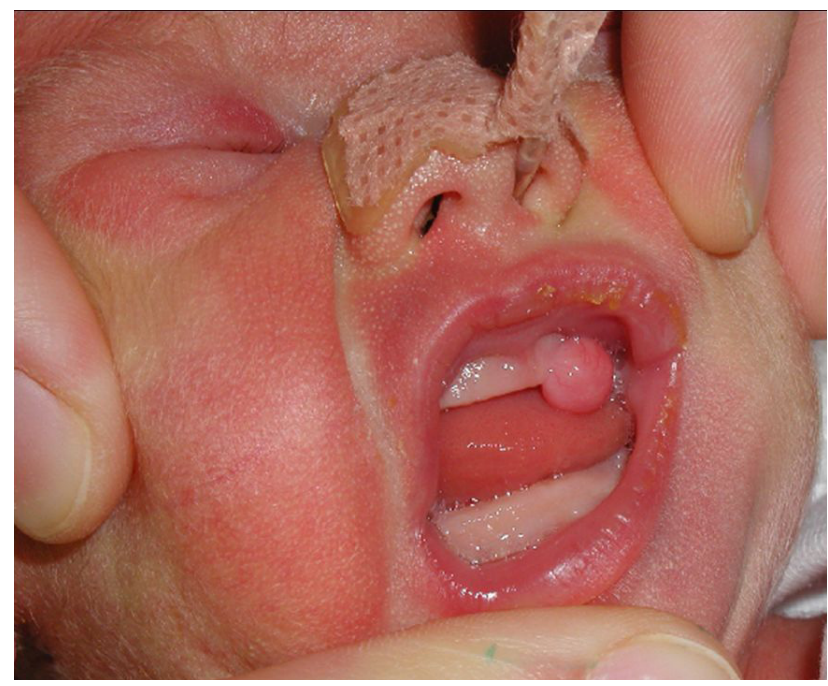

Fig. 2. Congenital epulis in preterm neonate.

In the preterm group, 102 infants were available for analysis. Their mean gestational age was 29.38 weeks, and their mean birthweight was $1148.9 \mathrm{~g}$. Altogether, ninety $(88.2 \%)$ of the preterm infants were delivered by cesarean section. In the full-term group, there were 87 infants with a mean gestational age of 39.36 weeks and a mean birthweight of $3418.6 \mathrm{~g}$. The majority of the full-term infants were delivered vaginally $(81.6 \%)$.

\section{Perinatal and neonatal variables}

Both perinatal variables (gestational age $(P<0.0001)$, mode of delivery $(P<0.0001)$, birthweight $(P<0.0001)$, Apgar score $(P<0.0001)$, resuscitation $(P<0.0001)$, laryngoscopy $[(P<0.0001))$ (Table 1$)$ and neonatal variables (antibiotic treatment $(P<0.0001)$, early and late infection $(P<0.0001))$ showed a significant association with prematurity and VLBW and ELBW (Table 1). Three preterm neonates and five full-term neonates were diagnosed with additional pathological conditions in their oral cavity. In preterm neonates, neonatal teeth (Fig. 1), congenital epulis (Fig. 2) and Epstein's pearls (Fig. 3) were established. Five full-term neonates had a sublingual frenum anomaly (frenulum linguae breve).

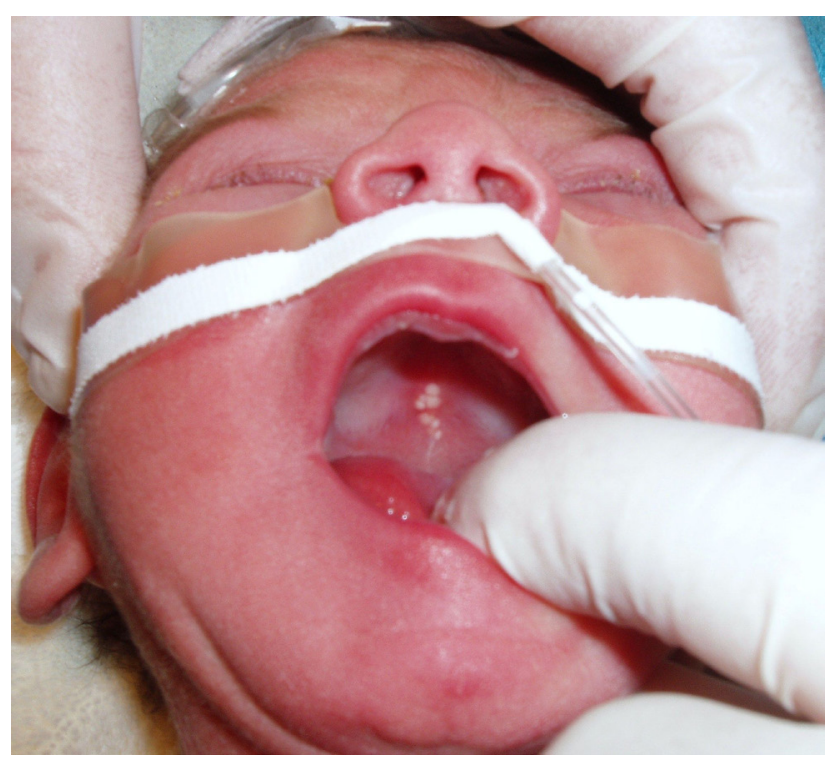

Fig. 3. Epstein's pearls in preterm neonate.

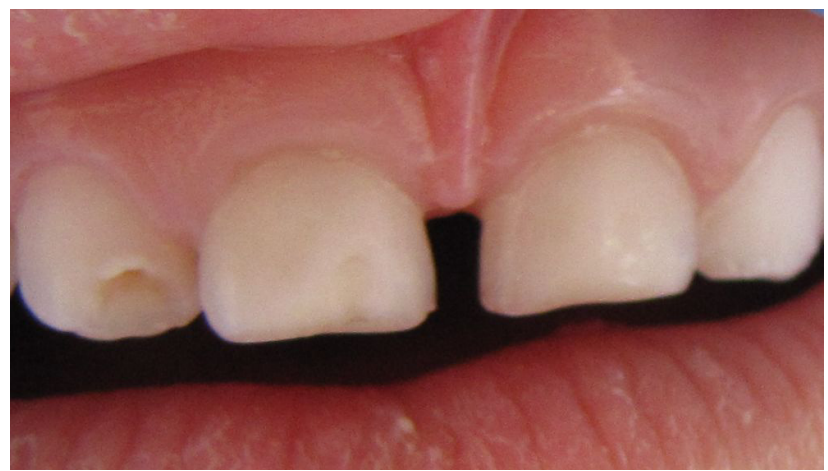

Fig. 4. DDE in one-year old infant.

\section{General health status}

The one-year-old preterm VLBW and ELBW infants suffered more frequently from general diseases $(P=0.001)$ and received more regular medication $(P=0.0196)$ than the full-term NBW group of infants (Table 1). In total, 24 one-year-old preterm VLBW and ELBW infants were diagnosed with neurological disorders, congenital heart defects, renal and respiratory conditions, and vision impairments. Regular medication (corticosteroids, antihistamine and antiepileptic drugs) was prescribed in eight VLBW and ELBW preterm one-year-old infants.

\section{Oral conditions}

One-year-old preterm VLBW and ELBW infants had a significantly fewer erupted primary teeth $($ mean $=6.01)$ compared to full-term NBW infants (mean=6.62) $(P=0.0333)$. The presence of DDE (Fig. 4) had a significant association with prematurity and VLBW and ELBW. The prevalence of enamel hypoplasia was $20.6 \%$, and the prevalence of opacities was $10.8 \%$ in one-year-old preterm VLBW and ELBW infants. The RR for enamel hypoplasia for preterm VLBW and ELBW infants was 5.9\%. The hard palate deformations diagnosed visually during examination were more often present in preterm VLBW and 
Table 2. Oral conditions in one-year old infants.

\begin{tabular}{|c|c|c|c|c|c|}
\hline $\begin{array}{c}\text { Variables } \\
\mathrm{n}(\%)\end{array}$ & Preterm & Full-term & $P$ & $\mathrm{RR}$ & $95 \% \mathrm{CI}$ \\
\hline \multicolumn{6}{|l|}{ Enamel hypoplasia* } \\
\hline No & $81(79.4)$ & $85(97.7)$ & \multirow{2}{*}{0.0006} & \multirow{2}{*}{5.8676} & \multirow{2}{*}{$1.4272-24.1238$} \\
\hline Yes & $21(20.6)$ & $2(2.3)$ & & & \\
\hline \multicolumn{6}{|l|}{ Enamel hypomineralization* } \\
\hline No & $91(89.2)$ & $84(96.6)$ & \multirow{2}{*}{ NS } & & \\
\hline Yes & $11(10.8)$ & $3(3.4)$ & & & \\
\hline $\mathrm{N}$ of erupted teeth: Mean $\pm \mathrm{SD}^{* * *}$ & $6.01 \pm 2.21$ & $6.62 \pm 2.59$ & 0.0333 & & \\
\hline \multicolumn{6}{|l|}{ Deformation of hard palate $* * * *$} \\
\hline No & $90(88.2)$ & $87(100.00)$ & \multirow{2}{*}{0.0008} & \multirow{2}{*}{21.3592} & \multirow{2}{*}{$1.2829-355.6263$} \\
\hline Yes & $12(11.8)$ & 0 & & & \\
\hline \multicolumn{6}{|l|}{ Oral pathology* } \\
\hline No & $99(97.1)$ & $82(94.3)$ & \multirow{2}{*}{ NS } & & \\
\hline Yes & $3(2.9)$ & $5(5.7)$ & & & \\
\hline
\end{tabular}

$\chi^{2}$ test, ${ }^{* * *}$ Mann-Whitney test, $* * * *$ Pearson test

$\mathrm{n}$ number, RR relative risk, SD standard deviation

ELBW infants $(P=0.0008)$, and the RR was calculated at 21.4 (Table 2).

\section{DISCUSSION}

Enamel hypomineralization and hypoplasia, tooth crown dimension changes, notching of the alveolar ridge, palatal grooving, high arched palate, cross bite, palatal asymmetry and a delay in dental development and eruption are the most frequent pathological oral conditions in preterm children ${ }^{19,20}$.

Oral pathological lesions in neonates represent a wide range of findings, the majority of which are asymptomatic and benign and can resolve themselves without treatment $^{21}$. In preterm VLBW and ELBW neonates, Epstein's pearls, congenital epulis and the presence of neonatal teeth were diagnosed. Epstein's pearls are nonodontogenic cysts; they are clinically asymptomatic and appear as nodules in the middle of the hard palate ${ }^{22}$. The presence of teeth in neonates is a rare condition in full-term infants and extremely rare in prematurely delivered infants ${ }^{23,24}$. In the present study, one preterm infant delivered with ELBW had an erupted lower incisor with hypermobility and inflammation of the surrounding gingiva. The tooth was extracted due to extreme mobility. Congenital epulis appears as a mass protruding through the oral cavity of a newborn child ${ }^{25,26}$. It arises from the alveolar mucosa and occurs more frequently in the maxilla, mainly in its frontal region, in the site of unerupted deciduous canines. Congenital epulis is usually a single lesion and consists of a smooth or tuberous ovoid mass connected by broad or narrow pendulum to the alveolar mucosa. The lesion has a pink or reddish color and varies in size from several millimeters to a few centimeters in diameter. An extremely large congenital epulis can cause complications even before birth. Obstruction of the infant's mouth might cause ineffective swallowing of amniotic fluid, resulting in poly- hydramnios. The preterm neonate with congenital epulis was treated surgically, and the lesion was completely removed.

DDE in primary and permanent dentition are wellstudied complications of prematurity. The exact etiology of DDE is not yet fully understood. The basic mechanism of DDE is the disturbed function of ameloblasts during different stages of amelogenesis. DDE are defined as alteration of dental enamel resulting from several disturbances during amelogenesis ${ }^{14}$. Enamel hypoplasia is a quantitative defect caused by incomplete deposition of immature enamel produced by ameloblasts during the secretory stage. Opacities or hypomineralization occur because of incomplete mineralization or maturation of the enamel ${ }^{27}$. Enamel defects could be genetic or environmentally caused by either local factors or systemic factors in the mother or child. DDE related to systemic factors have been thought to be associated with systemic diseases of VLBW and ELBW infants, such as nutritional problems, hypocalcemia ${ }^{28,29}$, neonatal infections and sepsis ${ }^{30}$, metabolic disorders, neonatal asphyxia ${ }^{28}$ or respiratory distress syndrome ${ }^{31}$. Aminabadi NA et al. ${ }^{32}$ found that decreased Apgar values were connected with the presence of DDE in primary dentition and concluded that the Apgar value can be used for the risk assessment of DDE in primary dentition. Many chemicals and drugs have the potential to damage ameloblasts and cause DDE $\left(\right.$ ref. $^{33}$ ). Levels of fluorides greater than $1 \mathrm{ppm}$ in the water, tetracycline and, more recently, amoxicillin have been implicated as a cause of DDE (ref. ${ }^{34}$ ). All preterm VLBW and ELBW infants in the present study received ampicilin during the neonatal period. In the case of antibiotics, it is difficult to distinguish the effect of fever and infection and the influence of amoxicillin on ameloblasts during enamel development. Local traumatic factors, such as laryngoscopy and endotracheal intubation, applied during the neonatal period may contribute to the occurrence of DDE in primary anterior teeth. In newborns, access to the 
trachea may be more difficult than in adults because of anatomic variations of the tongue, larynx and epiglottis. Orotracheal intubation trauma to oral tissue occurs during elevation of the laryngoscope blade to move back the tongue and expose the pharyngeal region. The pressure on the alveolar ridge can affect the primary teeth that are in the developmental phase of crown ${ }^{35}$. DDE arising from local causes tend to affect only single teeth or groups of teeth. The distribution of enamel defects within the dentition is usually localized to the anterior region of the maxillary teeth. Reports of DDE in preterm infants described in the literature were frequently connected with orotracheal intubation; however, Seow et al. ${ }^{6}$ suggested that laryngoscopy, rather than the endotracheal tube itself, may be a more significant cause of DDE. In a study conducted by Seow et al. ${ }^{6} 85 \%$ of intubated infants had DDE of maxillary anterior teeth compared to $21.7 \%$ of nonintubated infants. Previous studies have indicated a high prevalence of DDE in preterm infants ranging from $20 \%$ to $96 \%$. In the current study, the prevalence of enamel hypoplasia was $20.6 \%$, and enamel hypomineralization was $10.8 \%$. Enamel hypoplasia with porous and rough surfaces, combined with feeding problems, frequent intake of sugars, behavioral disorders and other risk factors, can predispose preterm children to dental caries ${ }^{36}$.

The timing of primary tooth eruption in premature infants has not been well established. Some authors ${ }^{37,38}$ have suggested that eruption of the first teeth is delayed in preterm infants. Viscardi et al. ${ }^{39}$ noted that primary tooth eruption occurred significantly later in infants with birthweight $<1000 \mathrm{~g}$ and gestational age $\leq 30$ weeks. These authors have suggested that factors related to the severity of neonatal illness and postnatal nutrition as well as the degree of prematurity affect the timing of primary teeth eruption. Seow et al. ${ }^{40}$ demonstrated that preterm VLBW infants have fewer teeth erupted compared to full-term NBW infants who were examined at the chronological age of 6 to 17 months. However, after 17 months of age, this difference was no longer evident, probably as a result of catch-up growth of the orofacial region. Seow et al. ${ }^{40}$ recommended using corrected age for the comparison of primary teeth eruption in preterm and full-term infants because preterm infants are not fully mature at the time of birth; therefore, the chronological age of preterm infants does not correspond to their actual biological age. In the present study, the corrected age was used to achieve a meaningful comparison with full-term infants. A significantly lower number of erupted primary incisors was established in preterm VLBW and ELBW infants with the corrected age of one year than in full-term NBW infants of chronological age one year in the current study.

Multiple factors can influence abnormal hard palate formation ${ }^{5}$. The narrow elongated head of preterm infants may cause a narrow high vaulted palate. The endotracheal tube may press on the midline palate and alveolar ridge, disturbing its growth. Pressure applied to the endotracheal tube to keep it properly positioned may further affect the developing palate. Infants suckling their endotracheal tubes may also result in some molding of the tissues.
According to Cortines and Costa ${ }^{41}$, the palatal groove occurs transiently in approximately one quarter of preterm infants. The palatal groove especially affects infants who have undergone a long stay in a neonatal intensive care unit, been intubated or used an orogastric tube. The incidence of palatal deformation increased with a longer use of tubes; the incidence was $87.5 \%$ in those neonates and infants requiring tubes for more than two weeks ${ }^{16}$. In the present study, the shape of the hard palate was visually evaluated during clinical examination, revealing a significant difference between the premature VLBW and ELBW groups and the full-term NBW group.

The authors of the present study are aware of certain limitations. A convenience sample of infants was used, in which significant differences may be due to the lack of statistical power of the sample, and only descriptive statistical analysis was used. Finally, it is worth noting that hereditary and individual factors associated with external factors, such as nutrition, pregnancy outcomes and maternal illnesses, can cause differences in the oral condition of infants.

\section{CONCLUSION}

This study confirmed anamnestic and medical differences between one-year-old preterm VLBW and ELBW infants and full-term NBW infants. Preterm birth of neonates with VLBW and ELBW is the risk factor of enamel hypoplasia, delayed primary teeth eruption and abnormal hard palate formation.

Acknowledgement: The study was supported by a grant from the Ministry of Health of the Czech Republic Conceptual Development of Research Organization (Faculty Hospital in Pilsen - FNP1, 00669806).

Author contributions: VM, RKI: contributed to the design of the study, oral examinations of all infants and interpretation of results; JD: performed the clinical examination of both groups of infants; VM, RKI, LH, ZB: analyzed the obtained data. All authors contributed to the preparation of the manuscript and approval of the final version.

Conflict of interest statement: The authors state that there is no conflict of interest regarding the publication of this article.

\section{REFERENCES}

1. World Health Organization. International classification of diseases and related health problems. $10^{\text {th }}$ revision. Geneva: World Health Organization, 2004.

2. Blencowe $H$, Krasevec J, de Oris M, Black RE, An X, Stevens GA. National, regional, and worldwide estimates of low birthweight in 2015, with trends from 2000: a systematic analysis. Lancet Glob Health 2019;7:e849-60.

3. Saigal S, Doyle LW. An overview of mortality and sequalae of preterm birth from infancy to adulthood. The Lancet 2008;371:261-9.

4. Hack M, Fanaroff AA. Outcomes of children of extremely low birthweight and gestational age in the 1990 s. Early Hum Dev 1999;53:193-218. 
5. Eastman DL. Dental outcomes of preterm infants. Newborn Infant Nurs Rev 2003;3(3):93-8.

6. Seow WK, Brown JP, Tudehope DI, O'Callaghan M. Developmental defects in the primary dentition of low-birth weight infants: adverse effects of laryngoscopy and prolonged endotracheal intubation. Pediatr Dent 1984;6:28-31.

7. Kim IH, Kang ChM, Song JS, Lee JH. Dental complications associated with neonatal intubation in preterm infants. J Dent Anesth Pain Med 2019;19(5):245-52.

8. Bodh M, Jain M, Dutta S, Namdev R, Kumar A. Preterm Birth Complications on Oro-Dental Structures: An Updated Review. J Oral Health Comm Dent 2015;9(2):85-9.

9. Paulsson L, Bondemark L, Söderfeidt B. A Systematic Review of the Consequences of Premature Birth on Palatal Morphology, Dental Occlusion, Tooth-Crown Dimensions, and Tooth Maturity and Eruption. Angle Orthod 2004;4(2):269-79.

10. Seow WK. Effects of preterm birth on oral growth and development. Aust Dent J 1997:42:85-91.

11. Franco KMD, Line SRP, de Moura-Ribeiro MVL. Prenatal and neonatal variables associated with enamel hypoplasia in deciduous teeth in low birth weight infants. J App Oral Sci 2007;15(6):518-23.

12. Seow WK, Humphrys C, Mahanonda R, Tudehope DI. Dental eruption in low birth-weight prematurely born children: a controlled study. Pediatr Dent 1988;10(1):39-42.

13. Ghanim A, Elfrink M, Weerheijm K, Mariño R, Manton D. A practical method for use in epidemiological studies on enamel hypomineralisation. Eur Arch Paediatr Dent 2015;16(3):235-46.

14. Federation Dentaire Internationale Commission on Oral Health, Research and Epidemiology: A review of developmental defects of enamel (DDE) index. Int Dent J 1992;42:411-2.

15. Merglova V, Dort J, Koberova - Ivancakova R. Prevalence of Developmental Enamel Defects of Primary Incisors in Preterm Infants delivered with Extremely Low Birth Weight. Int J Dentistry Oral Sci 2019;64:691-6.

16. Ehrenberg A, Nowak AJ. Palatal groove formation characteristics in neonates and infants with orotracheal tubes. Am J Dis Child 1984,138(10):974-5.

17. American Academy of Pediatrics. The Apgar score. Obstet Pract Pediatr 2006;117:1444-7.

18. Apgar V.The newborn scoring system: reflections and advice. Pediatr Clin North Am 1966;113:645-50.

19. D'Oliveira FFR, Martins MST, Duarte GMB. Oral Conditions in Very Low and Extremely Low Birth Weight Children. J Dent Child 2008;75(3):235-42.

20. Namdev R, Kumar A. Preterm Birth Complications On OroDental Structures: An Updated Review. J Oral Health Comm Dent 2015;9(2):85-9.

21. Patit $S$, Rao RS, Majumdar B, Jafer M, Maralingannavar M, Sukumaran A. Oral Lesions in Neonates. Int J Clin Pediatr Dent 2016;9(2):134-8.

22. Moda A. Gingival cyst of newborn. Int J Clin Pediatr Dent 2011;4(1):83-4
23. Merglova V. Nonsyndromic extremely premature eruption of teeth in preterm neonates - a report of three cases and a review of the literature. Case Reports in Perinatal Medicine 2018;7(2):20180006 doi:10.1515/crpm-2018-0006.

24. Cizmeci MN, Kanboruglu MK, Uzun FK, Tatli MM. Neonatal tooth in a preterm Infant. Eur J Pediatr 2013;172:279.

25. McGuire TP, Gomes PP, Freilich MM, Sándor GKB. Congenital Epulis: A Surprise in the Neonate. J Can Dent Assoc 2006;72:747-50.

26. Merglova V, Mukensnabl P, Andrle P. Congenital epulis. BMJ Case Reports 2012; 2012:bcz0120120483. doi: 10.1136/bcr. 012012.5483.

27. Jacobsen PE, Haubek D, Henriksen TB, Østergaard JR, Poulsen S. Developmental enamel defects in children born preterm: a systemic review. Eur J Oral Sci 2014;122(1):7-14.

28. Faerne JM, Bryan EM, Elliman AM, Brook AH, Williams DM. Enamel defects in the primary dentition of children born weighing less than 2000g. Br Dent J 1990;168(11):433-7.

29. Seow WK, Masel JP, Weir C, Tudehope DI. Mineral deficiency in the pathogenesis of enamel hypoplasia in prematurely born, very low birthweight children. Pediatr Dent 1989;11(4):297-302.

30. Funakoshi Y, KoshidaY, Hieda T. Dental observations of low - birth weight infants. Pediatr Dent 1981;3:21-5.

31. Johnsen D, Krejci C, Hack M, Fanaroff A. Distribution of enamel defects and the association with respiratory distress in very low birth weight infants. J Dent Res 1984;63:59-64.

32. Aminabadi NA, Farahani RMZ, Gajan EB. Apgar Index as a Correlate of Enamel Defects of Primary Dentition. Oral Health Prev Dent 2008;6(4):331-5.

33. Salanitri S, Seow WK. Developmental enamel defects in the primary dentition: aetiology and clinical management. Aust Dent J 2013;58:133-40.

34. Hong L, Levy SM, Warren JJ, Dawson DV, Bergus GR, Wefel JS. Association of amoxicilin use during early childhood with developmental tooth enamel defects. Arch Pediatr Adolesc Med 2005;159:943-8.

35. Matsumoto T, Carvalho WB. Tracheal intubation. J Pediatr 2007;83(2):83-90.

36. Sabel N, Klinberg G, Dietz W, Nietzche S, Norén JG. Polarized light and scanning electron microscopic investigation of enamel hypoplasia in primary teeth. Int J Paed Dent 2010;20:31-6.

37. Trupkin DP. Eruption patterns oft he first primary tooth in infants who were underweight at birth. J Dent Child 1974;41:279-82.

38. Golden NL, Takieddine F, Hirsch VJ. Teething age in premturely born infants. Am J Dis Child 1981;135:903-4.

39. Viscardi RM, Romberg E, Abrams RG. Delayed primary tooth eruption in premature infants: relationship to neonatal factors. Pediatr Dent 1994;16(1):23-8.

40. Seow WK, Humphrys C, Mahononda R, Tudehope DI. Dental eruption in low birth - weight prematurely born children: a controlled study. Pediatr Dent 1988;10(1):39-42.

41. Cortines AAO, Costa LR. Associated factors and persistence of palatal groove in preterm infants: a cohort study. BMC Pediatr 2016:16(1):143. 